Original Research Paper

\title{
Does it Get Better?: Childhood Bullying and the Positive Mental Health of LGBT Canadians in Adulthood
}

\author{
${ }^{1}$ Tamara Edkins, ${ }^{2}$ Tracey Peter, ${ }^{3}$ Catherine Taylor, ${ }^{4}$ Frank Cormier and ${ }^{5}$ Janice Ristock \\ ${ }^{1,2,4}$ Department of Sociology, University of Manitoba, Canada \\ ${ }^{3}$ Education and Rhetoric, Writing and Communication, University of Winnipeg, Canada \\ ${ }^{5}$ Women and Gender Studies, University of Manitoba, Canada
}

Article history

Received: 10-09-2017

Revised: $10-01-2018$

Accepted: 03-02-2018

\section{Corresponding Author:}

Tamara Edkins

Department of Sociology,

University of Manitoba,

Canada

Email: edkinst@myumanitoba.ca

\begin{abstract}
Globally, Lesbian, Gay, Bisexual, Transgender and Queer (LGBTQ) individuals are a highly discriminated group. Few academics have explored whether LGBTQ youth who experience discrimination can "get better", especially with respect to their positive mental health. Using minority stress theory, the current study explored whether there was a longterm relationship between childhood bullying and positive mental health in adulthood among LGBTQ individuals. The results suggest that there was a negative long-term relationship, wherein participants bullied in childhood displayed lower levels of positive mental health in adulthood. Suggestions for practices to promote positive mental health among LGBTQ individuals are then discussed, followed by suggestions for future research.
\end{abstract}

Keywords: LGBTQ, Minority Stress, Enacted Stigma, Positive Mental Health

\section{Introduction}

Lesbian, Gay, Bisexual, Transgender and Queer (LGBTQ) individuals make up one of the most discriminated against, stigmatized and excluded groups in Canada and internationally. Despite the enactment of legislation and policy in Canada protecting the rights and freedoms of LGBTQ individuals, the climate of homophobia and transphobia ingrained in Canadian culture has yet to be eliminated or, it might be argued, even significantly reduced.

Such a climate has been associated with increased mental health disorders among LGBTQ individuals; however, relatively few sociologists have explored the effects of anti-LGBTQ discrimination on the positive mental health of LGBTQ youth or adults and the majority of sociological studies have focused on shortterm effects. Even fewer studies have explored the longterm effects of prejudice experienced in adolescence on the state of mental health of LGBTQ individuals in adulthood. Hence, despite campaigns such as the "It Gets Better" project that encourages LGBTQ youth facing harassment that their lives will get better with time, we do not know whether "it" really does "get better" in adulthood. Therefore, the main sociological research question of the current project is: Does childhood bullying negatively affect or inhibit the formation of flourishing levels of positive mental health among LGBTQ individuals later in life?

\section{Review of the Literature}

A sociological theory commonly employed when discussing mental health disparities among minority groups in the literature, is minority stress theory (also referred to as "enacted stigma theory"). Minority stress theory focuses on how minority groups are incompatible with the dominant social structure in society, placing them at a disadvantage relative to the dominant group and subjecting them to discrimination and/or minority stressors such as anti-LGBTQ bullying. The theory holds that this then results in increased stress levels and promotes negative mental health among members of the minority group (Meyer, 1995; 2003).

The sociological literature is largely supportive of minority stress theory, demonstrating that there is a significant relationship between prejudice and the increased prevalence of mental health disorders among LGBTQ individuals, compared to their Cisgender Heterosexual (CH) peers. More specifically, the literature shows that LGBTQ individuals who have experienced enacted stigma are more likely to report negative mental health outcomes than are $\mathrm{CH}$ individuals (for review, see Collier et al., 2013). Further, although most studies have focused on mental health disorders and the short-term effects of minority stressors, some studies have also demonstrated how minority stress theory can be extended to consider positive mental health (for example, Frost and LeBlanc, 2014; Lyons et al., 2013), as well as 
the negative long-term effects of bullying on LGBTQ individuals later in life (Friedman et al., 2008; Josephson and Whiffen, 2007; Rivers, 2001; 2004).

Minority stress theory has also proposed control factors that can influence the relationship between minority stress and mental health among LGBTQ individuals, namely "outness", intersectionality and measures of LGBTQ-supportive and inclusive climates. First, "outness" refers to whether or not an individual has disclosed their LGBTQ identity. As minority stress theory posits and the literature demonstrates, concealing one's LGBTQ identity is a minority stressor in itself, in that individuals live with an oppressive fear of being "outed" which can affect their mental health (Meyer, 2003; Kosciw et al., 2015; Morris et al., 2001). Second, intersecting social locations can also influence the relationship of minority stress on the mental health of LGBTQ individuals (Meyer, 2003). For instance, studies have illustrated how gender identity ( $\mathrm{Su}$ et al., 2016; Szymanski et al., 2014), age (Kertzner et al., 2009; Wight et al., 2012) and religion (Dunbar, 2014; Gattis et al., 2014), for example, change the dynamics of minority stress, mental health and how these two measures interact within different social contexts. Finally, measures of LGBTQ-inclusive and supportive climates have also been associated with mitigating the effect of prejudice on LGBTQ individuals and their mental health. For instance, some studies demonstrate how LGBTQ-supportive or inclusive policies, programs or institutional supports can reduce the adverse effects of prejudice, as well as promote positive mental health among LGBTQ individuals (Hatzenbuehler and Keyes, 2013; Kosciw et al., 2013; Saewyc et al., 2014).

\section{Empirical Expectations}

Although sociologists have explored the relationship between mental health and prejudice among LGBTQ individuals, the literature shows that there are relatively few researchers who have explored the long-term relationship between positive mental health and prejudice-related experiences among LGBTQ adults. The purpose of the current study was to contribute to this literature and extend minority stress theory to consider the long-term relationship between childhood bullying and positive mental health in adulthood using a sample of Canadian adults. To address such a relationship, the current research followed the required analysis suggested by Schwartz and Meyer (2010). Based on their suggestions, four research questions were addressed in the current research and in turn, based on the literature and minority stress theory, four hypotheses were tested:

- Hypothesis 1: LGBTQ adults will have significantly lower levels of positive mental health compared to their $\mathrm{CH}$ counterparts
- Hypothesis 2: A higher percentage of LGBTQ adults will have experienced childhood bullying than $\mathrm{CH}$ adults

- Hypothesis 3: LGBTQ adults who have not experienced childhood bullying will exhibit similar levels of positive mental health to $\mathrm{CH}$ adults

- Hypothesis 4: Consistent with minority stress theory, childhood bullying will be negatively associated with positive mental health among LGBTQ adults

\section{Materials and Methods}

\section{Data}

The current study used data from the Every Teacher project, a national Canadian study that evaluates the presence and quality of LGBTQ-inclusive policies and practices in Canadian schools. The survey's target population included educators across all Canadian provinces and territories. The sample was obtained by contacting teacher organizations across Canada and asking them to recruit potential participants from their current members (Taylor et al., 2015). The organizations then contacted potential survey participants by e-mail, website notices, newsletters and in-person. Willing participants were given a link to access the survey online (Taylor et al., 2015). The final report for the Every Teacher project has more information on the survey development and data collection involved in this Canada-wide project (Taylor et al., 2015).

\section{Sample}

The sample included educators who answered the long-form version of the Every Teacher questionnaire that consisted of the main, "short-form" survey plus a set of supplementary questions. All respondents completed the short-form survey $(n=3319)$; fewer of them $(n=1974)$ went on to answer the supplementary questions. Because the main measures of the current study were asked in the supplementary questions, the sample is substantially reduced. Nevertheless, the sample size of 1,974 for the current research is sufficiently large. Of those respondents in this reduced sample who identified their sexual orientation/gender identity, the majority identified as $\mathrm{CH}$ $(80.4 \%, \mathrm{n}=1529)$, while one-fifth $(19.6 \%, \mathrm{n}=372)$ identified as LGBTQ. There were 73 participants who did not answer this question. Educators are not a representative sample of the Canadian workforce. The majority of educators are most likely middle-class and college-educated and therefore may have higher level of positive mental health since they are not subject to poverty-related stressors. Some educators, due to different social locations (e.g., single parent), may experience poverty-related stressors, but such a difference has not been accounted for in the current project. Sample demographics for LGBTQ and CH educators in the final sub-sample can be found in Table 1. 
Table 1: Sample description: LGBTQ vs. Cisgender Heterosexual $(\mathrm{CH})$ respondents (Unweighted)

\begin{tabular}{|c|c|c|}
\hline Current position & LGBTQ & $\mathrm{CH}$ \\
\hline Teachers & $90.3 \%$ & $87.8 \%$ \\
\hline Non-teachers & $6.2 \%$ & $6.9 \%$ \\
\hline Counselors & $3.5 \%$ & $5.3 \%$ \\
\hline \multicolumn{3}{|l|}{ Gender } \\
\hline Male & $46.8 \%$ & $24.1 \%$ \\
\hline Female & $53.2 \%$ & $75.9 \%$ \\
\hline Age (mean) & 41.13 & 40.94 \\
\hline \multicolumn{3}{|l|}{ Province } \\
\hline Alberta & $6.2 \%$ & $5.6 \%$ \\
\hline Atlantic provinces* & $9.4 \%$ & $14.9 \%$ \\
\hline British Columbia & $7.3 \%$ & $8.8 \%$ \\
\hline Manitoba & $27.2 \%$ & $42.9 \%$ \\
\hline Ontario & $42.5 \%$ & $16.3 \%$ \\
\hline Quebec & $1.9 \%$ & $1.3 \%$ \\
\hline Saskatchewan & $2.2 \%$ & $6.2 \%$ \\
\hline Territories** & $3.5 \%$ & $4.0 \%$ \\
\hline \multicolumn{3}{|l|}{ Race/Ethnicity } \\
\hline White & $87.3 \%$ & $90.4 \%$ \\
\hline Aboriginal & $6.2 \%$ & $6.3 \%$ \\
\hline Other racialized & $6.5 \%$ & $3.3 \%$ \\
\hline \multicolumn{3}{|l|}{ Employment contract } \\
\hline Permanent & $87.1 \%$ & $88.1 \%$ \\
\hline Term, casual, substitute & $12.9 \%$ & $11.9 \%$ \\
\hline School size (mean number of students) & $705(602.32)$ & $558(432.55)$ \\
\hline \multicolumn{3}{|l|}{ School location } \\
\hline Urban & $93.5 \%$ & $87.2 \%$ \\
\hline Rural & $6.5 \%$ & $12.8 \%$ \\
\hline \multicolumn{3}{|l|}{ School religious affiliation } \\
\hline Non-religious & $90.8 \%$ & $92.4 \%$ \\
\hline Catholic school & $9.2 \%$ & $7.6 \%$ \\
\hline
\end{tabular}

*Atlantic provinces include Prince Edward Island, Nova Scotia, New Brunswick and Newfoundland and Labrador.

**Territories include the Yukon, Nunavut and the Northwest Territories

\section{Measures}

\section{Positive Mental Health}

Positive mental health, the dependent variable, was measured by two separate variables. A dichotomous "flourishing/languishing" positive mental health variable was created, wherein flourishing levels of positive mental health were coded as 1. A 14-item Mental Health Continuum Short-Form (MHC-SF) index created by Corey Keyes was also used in the analysis (Keyes, 2002) ( $\alpha=0.912)$. The MHC-SF is an established tested and validated index for measuring emotional, psychological and social wellbeing (Peter et al., 2011).

\section{Childhood Bullying}

The main independent variable was childhood bullying. Childhood bullying was computed as a dummy and a discrete dummy variable. The dummy variable was a yes/no childhood bullying variable, wherein "yes, I have experienced childhood bullying" was coded as 1 . Childhood bullying was also re-computed into a discrete dummy variable measuring the impact of bullying. The impact categories included: not bullied (36\%), bullied with minimal impact (15\%), bullied with moderate impact (24\%), bullied with a severe impact at the time, but is now over it $(18 \%)$ and bullied with a severe impact that is still distressing for the respondent $(6 \%)$. The "not bullied" dummy category was excluded from the regression analysis and used as the reference category.

\section{Demographics}

Two demographic controls were used in the final analysis, including age and employment contract. Employment contract was coded into a dummy variable, with permanent contract coded as $1(87 \%)$ and the current age of respondents was coded as the stated age of a respondent in years. 
Table 2: Descriptive statistics: Independent measures

\begin{tabular}{|c|c|c|}
\hline Continuous measures & Mean & Standard deviation \\
\hline Age & 41.06 & 9.90 \\
\hline School safety & 0 & 1.00 \\
\hline LGBTQ support & 0 & 1.00 \\
\hline Dummy measures & $\%$ Yes & \\
\hline LGBTQ/CH & $19.6 \%$ (LGBTQ) & \\
\hline Childhood bullying & $64.0 \%$ & \\
\hline \multicolumn{3}{|l|}{ Past experiences of bullying } \\
\hline Not bullied (reference) & $36.0 \%$ & \\
\hline Minimal impact & $15.4 \%$ & \\
\hline Moderate impact & $23.9 \%$ & \\
\hline Severe bullying, but over it & $18.3 \%$ & \\
\hline Severe impact, but distressing & $6.4 \%$ & \\
\hline Employment status & $88.1 \%$ (Permanent) & \\
\hline Homophobic harassment policies & $66.4 \%$ & \\
\hline Transphobic harassment policies & $50.3 \%$ & \\
\hline Out to anyone at school* & $78.2 \%$ & \\
\hline
\end{tabular}

*LGBTQ respondents only.

\section{LGBTQ-Supportive or Inclusive Factors}

Five LGBTQ-supportive or inclusive factors were used in the final model: (1) Homophobic harassment policies, (2) Transphobic harassment policies, (3) Disclosure of LGBTQ identity, (4) Support for addressing LGBTQ issues in school and (5) perceived school safety for LGBTQ individuals. Homophobic and transphobic harassment policies, as well as disclosing one's LGBTQ identity were coded into dummy variables, with the presence of homophobic or transphobic harassment policies in one's school coded to 1 and indicating that one had disclosed one's LGBTQ identity to at least one person at school also coded to 1 . The perceived LGBTQ support index was computed from 4 items that asked respondents whether they thought they would receive support in addressing LGBTQ issues at school $(\alpha=0.82)$. The LGBTQ school safety index was computed from 6 items that asked respondents how safe they thought the school environment was for LGBTQ students $(\alpha=0.94)$. All indices or continuous variables were mean-centered and standardized into z-scores. Descriptive statistics for all continuous and dummy variables can be found in Table 2 .

\section{Analysis}

The following analyses were conducted using the Statistical Package for the Social Sciences (SPSS). In testing the first three hypotheses, chi-square was used to establish whether there were any significant difference between LGBTQ and CH participants on positive mental and childhood bullying. Cramer's V was used to measure the effect size of significant relationships. Multiple imputations were used to address the missing values in the first three parts of the analysis. Finally, the relationship between positive mental health and childhood bullying among LGBTQ adults was explored.
Using a hierarchical ordinary least-squares regression model, the current study looked at the effect of childhood bullying on positive mental health among LGBTQ respondents. An ordinary linear regression model was used because it requires a continuous dependent measure and using the hierarchical block enter method allows researchers to test for spurious effects between variables in the regression model (Tabachnick and Fidell, 2013). Three blocks were entered into the regression model in the following order: (1) demographic controls, (2) severity of childhood bullying and (3) LGBTQ-supportive or inclusive factors. To account for missing values, pairwise deletion was then employed in the regression model. Lastly, all analyses were weighted by province using a weighting algorithm in SPSS. For more information on the weighting procedures used in the analysis see Taylor et al. (2015) report on the Every Teacher dataset.

\section{Results}

Hypothesis 1: There was a significant association between positive mental health and LGBTQ or $\mathrm{CH}$ identity. More specifically, $\mathrm{CH}$ adults were significantly more likely to report flourishing levels of positive mental health than their LGBTQ peers $(69.9 \%$ Vs. $63.7 \%$, respectively, $\mathrm{p}<0.001)$. Therefore, the null hypothesis for the first research question can be rejected and the research hypothesis is supported. A gender-based interaction term was also noted. There was no significant difference between LGBTQ and CH males on positive mental health; however such a relationship was significant between female $\mathrm{CH}$ and LGBTQ respondents. LGBTQ females were significantly more likely than $\mathrm{CH}$ females to report lower mean scores on the positive mental health index (33.2\% Vs. $20.1 \%, \mathrm{p}<0.001)$. 
Hypothesis 2: There was a significant difference between LGBTQ and $\mathrm{CH}$ adults in terms of childhood bullying. LGBTQ adults were significantly more likely than $\mathrm{CH}$ adults to report experiencing in-school bullying in their childhood $(73.1 \%$ Vs. $62.0 \%, p<0.001)$. Therefore, the null hypothesis can be rejected and the research hypothesis for the second research question is supported. A gender interaction effect between CH/LGBTQ identity and childhood bullying was also noted. Specifically, among female participants, there were no significant differences between LGBTQ and CH adults in reporting experiences of childhood bullying (62.3 Vs. 59.5\%, p = 0.35). However, among male participants, the relationship found among the overall sample remained, in that LGBTQ male adults, on average, were significantly more likely than $\mathrm{CH}$ adults to report childhood bullying $(84.6 \%$ Vs. $72.5 \%, p<0.001)$.

Hypothesis 3: The relationship between childhood bullying and positive mental health among LGBTQ and $\mathrm{CH}$ adults was established. For both LGBTQ and $\mathrm{CH}$ non-bullied adults were significantly more likely to report flourishing levels of positive mental health than their bullied counterparts $(81.5 \%$ Vs. 57.1, $\mathrm{p}<0.001$; $73.7 \%$ Vs. $67.6 \%, \mathrm{p}<0.001$, respectively). Hence, the null hypothesis for the third research question can be rejected and the research hypothesis is confirmed; both non-bullied LGBTQ and non-bullied $\mathrm{CH}$ adults illustrate similar distributions in respect to their positive mental health. Notably, this relationship was stronger for LGBTQ than for $\mathrm{CH}$ participants, in that the difference between bullied and non-bullied participants was statistically very weak among $\mathrm{CH}$ adults $\left(\varphi_{c}=0.096\right)$; the difference between bullied and non-bullied LGBTQ participants demonstrated a moderate relationship between childhood bullying and positive mental health $\left(\varphi_{c}=0.231\right)$. The $\varphi$ symbol refers to the strength of the relationship between two variables.

Hypothesis 4: The final hierarchical OLS regression model has been noted in Table 3 . In controlling for other mitigating factors, minimal $(p<0.001)$, moderate $(\mathrm{p}<0.01)$ and severe-and-still-distressing $\quad(\mathrm{p}<0.001)$ categories of childhood bullying were significantly associated with positive mental health, in that compared to non-bullied respondents, participants who fell into these categories of severity were more likely to report lower levels of positive mental health. Minimal impact from bullying accounted for $30.1 \%$, moderate impact accounted for $15.5 \%$ and severe impact, but still distressing accounted for $18.1 \%$ of the variance of positive mental health among LGBTQ adults. Notably, the only childhood bullying category that was not significantly associated with positive mental health, was the category "severe impact from bullying, but over it."

Further, in regard to the demographic control variables, temporarily employed LGBTQ educators were significantly more likely to report higher levels of positive mental health than educators with permanent contracts. Finally, three of the LGBTQ-supportive climate measures were significant within the final model wherein: feeling supported in addressing LGBTQ issues in school $(p<0.01)$; the presence of transphobic harassment policies $(\mathrm{p}<0.01)$; and disclosing one's LGBTQ identity to someone at work $(\mathrm{p}<0.001)$ were all associated with higher levels of positive mental health.

Table 4 demonstrates how the original relationship changes after controlling for possible spurious effects. With the introduction of the first block in the linear regression model, looking at the adjusted $\mathrm{R}^{2}$ values, demographic controls only account for $1.1 \%$ of the variance of positive mental health $(\mathrm{p}<0.05)$. However, upon the introduction of the severity of childhood bullying measure the explained variance increases to $10.5 \%(\mathrm{p}<0.001)$ and finally, with the introduction of the third set of variables, namely the social support measures, the model accounts for $19.0 \%$ of the variance of positive mental health $(\mathrm{p}<0.001)$. There are limitations in the dataset in terms of the variables that we could use; and therefore, the model cannot account fully for the positive mental health of all the participants. However, future researchers can explore the effect of other variables on positive mental health and its relationship with childhood bullying.

Table 3: Overall OLS regression (PMH)

\begin{tabular}{lccc}
\hline Variable list & $B$ & $S E B$ & $\beta$ \\
\hline Employment status & -0.545 & 0.154 & $-0.172^{* * *}$ \\
Age & 0.009 & 0.006 & 0.069 \\
Minimal impact & -0.921 & 0.176 & $-0.301^{* * *}$ \\
Moderate impact & -0.396 & 0.154 & $-0.155^{* *}$ \\
Severe bullying, but over it & 0.084 & 0.160 & 0.030 \\
Severe impact & -0.643 & 0.193 & $-0.181^{* * *}$ \\
LGBTQ support & 0.154 & 0.062 & $0.131^{* *}$ \\
Homophobic harassment policies & -0.116 & 0.133 & -0.051 \\
Transphobic harassment policies & 0.449 & 0.141 & $0.185^{* *}$ \\
Out to anyone at school & 0.755 & 0.191 & $0.188^{* * *}$ \\
School Safety & 0.047 & 0.058 & 0.040 \\
\hline
\end{tabular}

Notes: $\mathrm{R}^{2}$ (adj.) $=0.213(0.190)^{* * *}, \mathrm{R}=0.462, \mathrm{n}=523$

$* \mathrm{p}=0.05 ; * * \mathrm{p}=0.01 ; * * * \mathrm{p}=0.001$ 
Table 4: Block input analysis of OLS linear regression

\begin{tabular}{|c|c|c|c|}
\hline & Block 1 & Block 2 & Block 3 \\
\hline Employment status & $-0.120 *$ & $-0.175 * *$ & $-0.172 * * *$ \\
\hline Age & 0.081 & 0.087 & 0.069 \\
\hline Minimal impact & & $-0.292 * * *$ & $-0.301 * * *$ \\
\hline Moderate impact & & $-0.163 * *$ & $-0.155^{* *}$ \\
\hline Severe bullying, but over it & & 0.020 & 0.030 \\
\hline Severe IMPACT & & $-0.225 * * *$ & $-0.181 * * *$ \\
\hline LGBTQ Support & & & $0.131 * *$ \\
\hline Homophobic harassment policies & & & -0.051 \\
\hline Transphobic harassment policies & & & $0.185 * *$ \\
\hline Out to anyone at school & & & $0.188 * * *$ \\
\hline School safety & & & 0.040 \\
\hline Notes. $\mathrm{R}^{2}(\operatorname{adj})=$. & $0.016(0.011)^{*}$ & $0.119(0.105)^{* * *}$ & $0.213(0.190)^{* * *}$ \\
\hline $\mathrm{R}=$ & 0.128 & 0.345 & 0.462 \\
\hline
\end{tabular}

\section{Discussion}

According to Schwartz and Meyer (2010), three key pieces of information are required to adequately support minority stress theory: First, to imply that there is a mental health disparity between minority and majority groups, the disadvantaged group should have a higher prevalence of negative mental health outcomes than their advantaged peers. Second, to maintain the disadvantaged position of the minority group, the minority group should be more likely to experience "prejudice-related stressors" than their advantaged group peers. Third, to solidify the effect of minority stress, there should be a relationship between the prejudice-related stressor and negative mental health outcome among disadvantaged group members.

Using Schwartz and Meyer's (2010) criteria, there was a positive mental health disparity between LGBTQ and $\mathrm{CH}$ adults. That is, $\mathrm{CH}$ adults were significantly more likely to report a flourishing state of positive mental health than were their LGBTQ peers. According to minority stress theory, such a disparity has emerged from a social climate of heteronormativity and cisgenderism that has placed LGBTQ individuals at a disadvantage compared to $\mathrm{CH}$ individuals, which can negatively affect an LGBTQ individuals' ability to think positively and function productively in society. However, it is important to point out, that even though LGBTQ adults were less likely to be flourishing, the majority of LGBTQ respondents (63.7\%) were nevertheless flourishing in terms of their positive mental health. Thus, although LGBTQ individuals have to endure a dominant social climate of heteronormativity and cisgenderism, most still flourish in society. Further, upon taking gender differences into account, the positive mental health disparity noted in the overall sample existed between LGBTQ and CH women; this disparity did not appear when comparing LGBTQ and $\mathrm{CH}$ men. Canadian studies have illustrated that mental health disparities can be more persistent among LGBTQ women than men in respect to certain mental health issues (Galliher et al., 2004); however, few studies have offered explanations for such gender differences.

Second, based on the results, LGBTQ adults were significantly more likely to report childhood bullying than their $\mathrm{CH}$ peers. The results are consistent with the previous literature that reports that LGBTQ youth are more likely than $\mathrm{CH}$ to experience in-school bullying (Taylor et al., 2011); it would then follow that LGBTQ individuals would be more likely to recall such experiences in adulthood. Further, due to the homophobia and transphobia ingrained in the social structure, LGBTQ individuals would be more likely to experience prejudice-related stressors; that is, stressors that go beyond the general stressors that $\mathrm{CH}$ individuals will experience in their everyday lives. Further, upon taking gender difference into account, LGBTQ males were significantly more likely to report childhood bullying than were $\mathrm{CH}$ males; however such a difference did not emerge in comparing LGBTQ and $\mathrm{CH}$ females (similar to results found by Robinson et al., 2013). One potential explanation could be that society is more hostile to men who defy gender conventions than to women, which would lead to LGBTQ males experiencing more bullying due to gender nonconforming behavior (Hort et al., 1990). Alternatively, as noted by D'Augelli and Hershberger (1993) gay boys are more likely to disclose their gay identity at an earlier age, which has been associated with an increased frequency of in-school bullying. In other studies, such as Kattari et al. (2016) study on anti-LGBTQ housing discrimination, as the number of years since an individual had disclosed increased, so did their chance of experiencing housing discrimination (Swank et al., 2013). However, based on the current results, it is not appropriate to assert that LGBTQ women are less likely to experience prejudicerelated stressors compared to LGBTQ men. As numerous Canadians studies demonstrate, LGBTQ females can be even more likely to experience various forms of discrimination than both LGBTQ and $\mathrm{CH}$ men, as well as CH women (Taylor et al., 2011; Peter et al., 2015; Saewyc et al., 2007). 
Third, the effect of minority stress on the mental health of LGBTQ individuals was further solidified in comparing non-bullied LGBTQ and non-bullied $\mathrm{CH}$ adults in respect to their positive mental health. In comparing non-bullied LGBTQ participants to non-bullied $\mathrm{CH}$ participants, nonbullied LGBTQ did resemble their non-bullied $\mathrm{CH}$ counterparts in terms of their positive mental health. As suggested by the current results, when LGBTQ individuals have avoided minority stressors, their stress levels and in turn, their positive mental health can resemble and even exceed the positive mental health of their dominant group peers (Bontempo and D'Augelli, 2002; Birkett et al., 2009).

Further, as noted by the third analysis, childhood bullying has a negative long-term effect on the positive mental health of both LGBTQ and CH adults. However, in comparison, childhood bullying had a harsher effect on LGBTQ adults. Although all human beings experience stressors throughout their lives, both LGBTQ and $\mathrm{CH}$ adults alike, minority-related stressors experienced in childhood can increase LGBTQ people's stress levels beyond the general stress of their dominant group peers. Consistent with the previous literature (Felix et al., 2009; Swearer et al., 2008), such increased levels of stress can have harsh effects on LGBTQ individuals and their mental wellbeing that exceed those experienced by their bullied $\mathrm{CH}$ counterparts.

Finally, according to Schwartz and Meyer (2010) and as noted above, the current research solidified the effect of minority stress on positive mental health, by confirming that there is a relationship between childhood bullying and lower levels of positive mental health among LGBTQ individuals. However, this relationship was shaped by the severity of childhood bullying noted by participants.

Surprisingly, the strongest negative association between positive mental health and childhood bullying was among LGBTQ adults who reported a minimal impact from bullying. As noted in the literature (Adams et al., 2005), LGBTQ individuals often minimize experiences of prejudice or discrimination and dissociate such experiences of prejudice from the larger social issues of homophobia and transphobia. Therefore, LGBTQ individuals who reported a minimal impact from childhood bullying may have underestimated the stress or negative effects prejudice had on their positive mental health and in turn, they may have underestimated the support or resources required to truly "get over" or cope with such experiences in their childhood (as discussed by Taylor et al., 1996).

In comparing the two groups of severely bullied participants, respondents who indicated they were over their severe experiences of bullying resembled the positive mental health levels of non-bullied participants; however, among participants who were still distressed from their severe experiences of bullying, childhood bullying had a negative effect on their positive mental health compared to their non-bullied peers. Following minority stress theory, the difference between these two groups makes sense, in that for the "over it" group the severe impact from childhood bullying is no longer a minority stressor and therefore has no effect on their positive mental health in adulthood; whereas for the "still distressed" group the severe impact continues to be a stressor and in turn, can still negatively affect their positive mental health.

There were also several control factors that promoted a flourishing state of positive mental health of LGBTQ adults in the current sample, including "outness", support in addressing LGBTQ-related issues in school and anti-discrimination policies. Consistent with the previous literature (Kosciw et al., 2015; Morris et al., 2001), disclosing one's LGBTQ identity was associated with higher levels of positive mental health among LGBTQ adults. Concealing one's LGBTQ identity has been described as a secondary minority stressor, in that concealing one's LGBTQ identity can create a fear of being "outed" and in turn, can negatively affect mental health, or, as demonstrated by the current results, can inhibit the formation of flourishing levels of positive mental health (Meyer, 2003).

Further, working in an environment with antidiscrimination policies and support for addressing LGBTQ issues also allowed LGBTQ adults to better thrive and flourish in respect to their positive mental health. Only the presence of transphobic harassment policies was related to higher levels of positive mental health, while, in contrast to the previous literature (Kosciw et al., 2013; Peter et al., 2016), homophobic harassment policies had no significant effect on LGBTQ individuals' mental health. One potential explanation could be that transphobic harassment policies are a fairly recent emergence that typically appears in policies that go beyond harassment to include various accommodation issues, whereas homophobic harassment policies often exist in isolation, suggesting that the presence of transphobic harassment policies may characterize a climate that is more supportive of the LGBTQ community in general.

Having support in addressing LGBTQ issues in the workplace also helped LGBTQ adults to flourish in respect to their positive mental health. When LGBTQ educators feel that they have such support from administration or co-workers in addressing LGBTQrelated issues in the classroom, it can potentially reduce the stress that educators feel in anticipating homophobic or transphobic backlash from parents, religious institutions or school personnel accusing LGBTQ educators of "pushing the gay agenda" (as discussed in Malins, 2016; Martino and Cumming-Potvin, 2011; 2014).

In essence, working in a LGBTQ-supportive and inclusive climate that reduces stress and anxiety and 
increases the gratification one feels as a worker, can allow LGBTQ individuals to better cope with minority stressors by having visible supports in the workplace that will ensure that when homophobic or transphobic prejudice does occur in the workplace it will be addressed and counteracted wherever possible. However, although such factors acted as protective factors for the positive mental health of LGBTQ adults, they did not substantially mitigate the negative long-term effects childhood bullying had on the positive mental health of LGBTQ individuals within the current sample. As illustrated in a previous study (Saewyc et al., 2014), it may take more time for inclusive policies and supportive practices to shift workplace climates to the extent that they positively affect the mental health of LGBTQ individuals.

\section{Recommendations for Future Research, Policy and Practice}

Future research should explore the long-term relationship between enacted stigma and positive mental health using a more representative sample of LGBTQ adults, or it should be explored using other samples of LGBTQ adults in Canada or in other countries. Future research should also attempt to understand what factors moderate or alleviate the stress associated with past experiences of childhood bullying or enacted stigma among LGBTQ adults and in turn, explore how this can affect positive mental health.

In terms of recommendations for policy and practice, anti-LGBTQ bullying needs to be better addressed in Canadian schools and in the broader social structure. As noted previously, LGBTQ youth experience more bullying than their $\mathrm{CH}$ peers and in turn, LGBTQ youth experience the consequences of bullying more than their $\mathrm{CH}$ peers (Taylor et al., 2011). Research suggests encouraging positive LGBTQ-inclusive environments through implementing Gay-Straight Alliances (Toomey et al., 2011), inclusive curriculums (Taylor et al., 2011) and bullying and anti-harassment policies (Russell et al., 2011), as well as encouraging educators to be supportive of LGBTQ students (Kosciw and Diaz, 2008). However, as argued by Malins (2016), the onus is not solely on educators to implement LGBTQ-inclusive education in schools; networks involving principals, school boards and other school personnel need to be engaged to support educators in using education to promote change and social justice.

Finally, anti-LGBTQ bullying in schools is not only a problem that affects LGBTQ individuals only in childhood, it is also an issue that affects them in their adulthood. Using campaigns such as the "It Gets Better" project to encourage LGBTQ youth to "keep going" or to "not give up" may have short-term effects in increasing the morale of bullied LGBTQ youth. Thinking about how social services, supportive resources and society as a whole can help LGBTQ adults to "get over" these discriminatory experiences in their childhood, can ultimately help them lead healthier, happier lives.

\section{Limitations}

Although the importance and novelty of the research findings is evident, there are limitations that must be noted. First, the current sample consists of Canadian educators who responded to a non-random recruitment campaign and therefore the generalizability of the current results is not representative of Canadians. Selfreport bias and recall bias also add statistical error to the current data; however as found in previous studies (Rivers, 2001), recalling experiences of childhood bullying does not invite much recall bias or error. Further, although self-report bias allows participants to, in part, define the situation, the current study is not concerned with objective definitions of bullying, but is focused on how those experiences are rated or remembered by participants themselves.

Ultimately, despite the limitations of the current sample, obtaining a substantive number of LGBTQ and $\mathrm{CH}$ individuals in one research sample, particularly within a sample of adults, is a difficult task (as noted by Meyer and Wilson, 2009; Moradi et al., 2009). Therefore, despite the potential for statistical bias or error, as well as the unrepresentative, sample of Canadians, in conducting a preliminary or exploratory study as to extend minority stress theory, the sample employed in the current study represents an adequate sample of Canadians, both LGBTQ and CH alike.

\section{Concluding Remarks}

Childhood is a critical period of development and growth. A traumatic experience or negative state of mental health in youth can affect how individuals fare later in life (as discussed in Petterson et al., 2016). Therefore, although it does "get better" for some youth, who find avenues to work through the bullying they have experienced, it clearly does not "get better" for all LGBTQ individuals who have experienced such stress in their youth. For some LGBTQ youth, such childhood experiences can continuously weigh upon their state of positive mental health, suppressing it well into adulthood. Campaigns such as the "It Gets Better" project should direct their focus not only on inspiring hope in bullied LGBTQ youth, but in providing them with support and resources. Ultimately, though, it is not enough to tell these individuals that it will "get better" and it is not even enough to help survivors heal. Schools must promote a social climate of inclusion, support and acceptance for the LGBTQ community, so that LGBTQ youth no longer have to be told that "it does get better", because it will already "be better" in their youth. 


\section{Acknowledgment}

I would like to acknowledge the Social Science and Humanities Council (SSHRC) for providing funding for this project.

\section{Author Contributions}

All authors contributed equally to the work required to complete this manuscript.

\section{Ethics}

There are no forseeable ethical issues that may arise from the publication of this manuscript.

\section{References}

Adams, E.M., B.J. Cahill and S.J. Ackerlind, 2005. A qualitative study of Latino lesbian and gay youths' experiences with discrimination and the career development process. J. Vocat. Behav., 66: 199-218. DOI: $10.1016 / j$.jvb.2004.11.002

Bontempo, D.E. and A. D'Augelli, 2002. Effects of atschool victimization and sexual orientation on lesbian, gay, or bisexual youths' health risk behavior. J. Adolescent Health, 30: 364-374. DOI: $10.1016 / \mathrm{S} 1054-139 \mathrm{X}(01) 00415-3$

Birkett, M., D.L. Espelage and B. Koenig, 2009. LGB and questioning students in schools: The moderating effects of homophobic bullying and school climate on negative outcomes. J. Youth Adolescence, 38: 989-1000. DOI: 10.1007/s10964-008-9389-1

Collier, K.L., G. van Beusekom, H.M. Bos and T.G. Sandfort, 2013. Sexual orientation and gender identity/expression related peer victimization in adolescence: A systematic review of associated psychosocial and health outcomes. J. Sex Res., 50: 299-317. DOI: 10.1080/00224499.2012.750639

D'Augelli, A.R. and S.L. Hershberger, 1993. Lesbian, gay and bisexual youth in community settings: Personal challenges and mental health problems. Am. J. Community Psychol., 21: 421-448. DOI: $10.1007 / \mathrm{BF} 00942151$

Dunbar, J.D.P., 2014. Religious frameworks as obstacles to healthy self-identity development and selfdisclosure of LGBTQ individuals. Dissertation.

Felix, E.D., M.J. Furlong and G. Austin, 2009. A cluster analytic investigation of school violence victimization among diverse students. J. Interpersonal Violence, 24: 1673-1695.

Friedman, M.S., M.P. Marshal, R. Stall, J. Cheong and E.R. Wright, 2008. Gay-related development, early abuse and adult health outcomes among gay males. AIDS Behav., 12: 891-902. DOI: $10.1007 / \mathrm{s} 10461-007-9319-3$
Frost, D.M. and A.J., LeBlanc, 2014. Nonevent stress contributes to mental health disparities based on sexual orientation: Evidence from a personal projects analysis. Am. J. Orthopsychiatry, 84: 557-557.

Galliher, R.V., S.S. Rostosky and H.K. Hughes, 2004. School belonging, self-esteem and depressive symptoms in adolescents: An examination of sex, sexual attraction status and urbanicity. J. Youth Adolescence, 33: 235-245.

Gattis, M.N., M.R. Woodford and Y. Han, 2014. Discrimination and depressive symptoms among sexual minority youth: Is gay-affirming religious affiliation a protective factor? Arch. Sexual Behav., 43: 1589-1599. DOI: 10.1007/s10508-014-0342-y

Hatzenbuehler, M.L. and K M. Keyes, 2013. Inclusive antibullying policies and reduced risk of suicide attempts in lesbian and gay youth. J. Adolescent Health, 53: 21-26. DOI: 10.1016/j.jadohealth.2012.08.010

Hort, B.E., B. Fagot and M.D. Leinbach, 1990. Are people's notions of maleness more stereotypically framed than their notions of femaleness? Sex Roles, 23: 197-212. DOI: 10.1007/BF00289866

Josephson, G. and V. Whiffen, 2007. An integrated model of gay men's depressive symptoms. Am. J. Men's Health, 1: 60-72. DOI: $10.1177 / 1557988306295795$

Kattari, S.K., D.L. Whitfield, N.E. Walls, L. Langenderfer-Magruder and D. Ramos, 2016. Policing gender through housing and employment discrimination: Comparison of discrimination experiences of transgender and cisgender LGBQ individuals. J. Society Soc. Work Res., 7: 427-447. DOI: $10.1086 / 686920$

Kertzner, R.M., I.H. Meyer, D.M. Frost and M.J. Stirratt, 2009. Social and psychological well-being in lesbians, gay men and bisexuals: The effects of race, gender, age and sexual identity. Am. J. Orthopsychiatry, 79: 500-510. DOI: $10.1037 / \mathrm{a} 0016848$

Keyes, C.L., 2002. The mental health continuum: From languishing to flourishing in life. J. health Soc. Behav., 43: 207-222. DOI: 10.2307/3090197

Kosciw, J.G. and E.M. Diaz, 2008. Involved, Invisible, Ignored: The Experiences of Lesbian, Gay, Bisexual and Transgender Parents and Their Children in Our Nation's K-12 Schools. 1st Edn., GLSEN, New York.

Kosciw, J.G., N.A. Palmer, R.M. Kull and E.A. Greytak, 2013. The effect of negative school climate on academic outcomes for LGBT youth and the role of in-school supports. J. School Violence, 12: 45-63. DOI: $10.1080 / 15388220.2012 .732546$

Kosciw, J.G., N.A. Palmer and R.M. Kull, 2015. Reflecting resiliency: Openness about sexual orientation and/or gender identity and its relationship to well-being and educational outcomes for LGBT students. Am. J. Community Psychol., 55: 167-178. DOI: 10.1007/s10464-014-9642-6 
Lyons, A., M. Pitts and J. Grierson, 2013. Factors related to positive mental health in a stigmatized minority an investigation of older gay men. J. Aging Health, 25: 1159-1181. DOI: 10.1177/0898264313495562

Malins, P., 2016. How inclusive is "inclusive education" in the Ontario elementary classroom?: Teachers talk about addressing diverse gender and sexual identities. Teaching Teacher Educ., 54: 128-138. DOI: $10.1016 /$ j.tate.2015.11.004

Martino, W. and W. Cumming-Potvin, 2011. They didn't have out there gay parents-they just looked like normal regular parents": Investigating teachers' approaches to addressing same-sex parenting and non-normative sexuality in the elementary school classroom. Curriculum Inquiry, 41: 480-501.

DOI: $10.1111 / \mathrm{j} .1467-873 X .2011 .00557 . \mathrm{X}$

Martino, W. and W. Cumming-Potvin, 2014. Teaching about sexual minorities and "princess boys": A queer and trans-infused approach to investigating LGBTQ-themed texts in the elementary school classroom. Discourse Stud. Cultural Politics Educ. DOI: 10.1080/01596306.2014.940239

Meyer, I.H., 1995. Minority stress and mental health in gay men. J. Health Soc. Behav., 36: 38-56. DOI: $10.2307 / 2137286$

Meyer, I.H., 2003. Prejudice, social stress and mental health in lesbian, gay and bisexual populations: conceptual issues and research evidence. Psychol. Bull., 129: 674-674.

Meyer, I.H. and P.A. Wilson, 2009. Sampling lesbian, gay and bisexual populations. J. Counsel. Psychol., 56: 23-23.

Moradi, B., J.J. Mohr, R.L. Worthington and R.E. Fassinger, 2009. Counseling psychology research on sexual (orientation) minority issues: Conceptual and methodological challenges and opportunities. J. Counsel. Psychol., 56: 5-5.

Morris, J.F., C.R., Waldo and E.D. Rothblum, 2001. A model of predictors and outcomes of outness among lesbian and bisexual women. Am. J. Orthopsychiatry, 71: 61-61.

Peter, T., L.W. Roberts and J. Dengate, 2011. Flourishing in life: An empirical test of the dual continua model of mental health and mental illness among Canadian university students. Int. J. Mental Health Promotion, 13: 13-22.

DOI: $10.1080 / 14623730.2011 .9715646$

Peter, T., C. Taylor, J. Ristock and T. Edkins, 2015. Pride and prejudice: Factors affecting school attachment among lesbian, bisexual and heterosexual girls. J. lesbian Stud., 19: 249-273.

Peter, T., C. Taylor and C. Campbell, 2016. You can't break... when you're already broken": The importance of school climate to suicidality among LGBTQ youth. J. Gay Lesbian Mental Health, 20: 1-19.

DOI: $10.1080 / 19359705.2016 .1171188$
Petterson, L.J., D.P. VanderLaan and P.L. Vasey, 2016. Sex, sexual orientation, gender atypicality and indicators of depression and anxiety in childhood and adulthood. Arch. Sex. Behav., 46: 383-1392. DOI: $10.1007 / \mathrm{s} 10508-016-0690-\mathrm{x}$

Rivers, I., 2001. The bullying of sexual minorities at school: Its nature and long-term correlates. Educ. Child Psychol., 18: 32-46.

Rivers, I., 2004. Recollections of bullying at school and their long-term implications for lesbians, gay men and bisexuals. Crisis, 25: 169-175. DOI: $10.1027 / 0227-5910.25 .4 .169$

Robinson, J.P., D.L. Espelage and I. Rivers, 2013. Developmental trends in peer victimization and emotional distress in LGB and heterosexual youth. Pediatrics, 131: 423-430. DOI: $10.1542 /$ peds.2012-2595

Russell, S.T., C. Ryan, R.B. Toomey, R.M., Diaz and J. Sanchez, 2011. Lesbian, gay, bisexual and transgender adolescent school victimization: Implications for young adult health and adjustment. J. School Health, 81: 223-230. DOI: $10.1111 /$ j.1746-1561.2011.00583.X

Saewyc, E., C. Poon, N. Wang, Y. Homma and A. Smith et al., 2007. Not Yet Equal: The Health of Lesbian, Gay and Bisexual Youth in BC. 1st Edn., McCreary Centre Society, Burnaby, pp: 50.

Saewyc, E.M., C. Konishi, H.A. Rose and Y. Homma, 2014. School-based strategies to reduce suicidal ideation, suicide attempts and discrimination among sexual minority and heterosexual adolescents in Western Canada. Int. J. Child, Youth Family Stud., 5: 89-89.

DOI: $10.18357 /$ ijcyfs.saewyce.512014

Schwartz, S. and I.H., Meyer, 2010. Mental health disparities research: The impact of within and between group analyses on tests of social stress hypotheses. Soc. Sci. Med., 70: 1111-1118. DOI: 10.1016/j.socscimed.2009.11.032

Su, D., J.A. Irwin, C. Fisher, A. Ramos and M. Kelley et al., 2016. Mental health disparities within the LGBT population: A comparison between transgender and nontransgender individuals. Transgender Health, 1: 12-20. DOI: 10.1089/trgh.2015.0001

Swank, E., B. Fahs and D.M. Frost, 2013. Region, social identities and disclosure practices as predictors of heterosexist discrimination against sexual minorities in the United States. Sociol. Inquiry, 83: 238-258. DOI: $10.1111 /$ soin. 12004

Swearer, S.M., R.K. Turner, J.E. Givens and W.S. Pollack, 2008. You're so gay!": Do different forms of bullying matter for adolescent males? School Psychol. Rev., 37: 160-160.

Szymanski, D.M., T.L. Dunn and A.S. Ikizler, 2014. Multiple minority stressors and psychological distress among sexual minority women: The roles of rumination and maladaptive coping. Psychol. Sexual Orient. Gender Diversity, 1: 412-412. 
Tabachnick, B.G. and L.S. Fidell, 2013. Using Multivariate Statistics. 6th Edn., Pearson Education, Boston, ISBN-10: 0205849571, pp: 983.

Taylor, C., T. Peter, T.L. McMin, T. Elliott and S. Beldom et al., 2011. Every Class in Every School: Final Report on the First National Climate Survey on Homophobia, Biphobia and Transphobia in Canadian Schools. 1st Edn., Egale Canada Human Rights Trust, Toronto.

Taylor, C., T. Peter, C. Campbell, E. Meyer and J. Ristock et al., 2015. The Every Teacher Project on LGBTQ-Inclusive Education in Canada's K-12 Schools: Final Report. 1st Edn., Manitoba Teachers' Society, Winnipeg.
Taylor, D.M., K.M. Ruggiero and W.R. Louis, 1996. Personal/group discrimination discrepancy: Towards a two-factor explanation. Canadian J. Behav. Sci., 28: 193-193. DOI: 10.1037/0008-400X.28.3.193

Toomey, R.B. C. Ryan, R.M. Diaz and S.T. Russell, 2011. High school Gay-Straight Alliances (GSAs) and young adult well-being: An examination of GSA presence, participation and perceived effectiveness. Applied Dev. Sci., 15: 175-185. DOI: $10.1080 / 10888691.2011 .607378$

Wight, R.G., A.J. LeBlanc, B. De Vries and R. Detels, 2012. Stress and mental health among midlife and older gay-identified men. Am. J. Public Health, 102: 503-510. DOI: 10.2105/AJPH.2011.300384 